\title{
Evaluation of premature senescence and senescence biomarkers in carcinoma cells and xenograft mice exposed to single or fractionated irradiation
}

\author{
BONG CHO KIM ${ }^{1 *}$, HEE JUNG YOO ${ }^{1 *}$, HYUNG CHUL LEE ${ }^{1,5^{*}}$, KYOUNG-AH KANG $^{1}$, \\ SEUNG HEE JUNG ${ }^{1,6}$, HAE-JUNE LEE ${ }^{2}$, MINYOUNG LEE ${ }^{2}$, SEUNGWOO PARK ${ }^{3}$, \\ YOUNG-HOON JI ${ }^{3}$, YUN-SIL LEE ${ }^{4}$, YOUNG-GYU KO ${ }^{5}$ and JAE-SEON LEE ${ }^{1,6}$

\begin{abstract}
${ }^{1}$ Research Center for Radio-senescence, ${ }^{2}$ Division of Radiation Effects, ${ }^{3}$ Research Center for Radiotherapy, Korea Institute of Radiological and Medical Sciences, Seoul; ${ }^{4}$ School of Pharmaceutical Sciences, Ewha Womans University, Seoul; ${ }^{5}$ Division of Life Sciences, Korea University, Seoul; ${ }^{6}$ Division of Biomedical Sciences, College of Medicine, Inha University, Incheon, Republic of Korea
\end{abstract}

Received December 18, 2013; Accepted February 3, 2014

DOI: $10.3892 /$ or.2014.3069

\begin{abstract}
The purpose of the present study was to elucidate whether premature senescence contributes to the outcome of radiotherapy (RT) and to validate senescence biomarkers in vitro and in vivo. Cultured human cancer cell lines and xenografted mice were exposed to single (SR; 2, 6 or $12 \mathrm{~Gy}$ ) or fractionated radiation (FR; 3 x 2 Gy or $6 \times 2$ Gy), and premature senescence was assessed using senescence-associated $\beta$-galactosidase (SA- $\beta$-Gal) activity, hypophosphorylation of $\mathrm{pRb}$ and $\mathrm{p} 21$ accumulation. A variety of senescence-associated biomarkers including cathepsin D (CD), the eukaryotic translation elongation factors eEF1A1, eEF1B2, decoy receptor 2 and Decl were further validated in vivo or in vitro. We demonstrated the beneficial tumor suppressive role of ionizing radiation (IR)-induced premature senescence in vitro and in vivo. FR inhibited tumor growth via induction of premature senescence as effectively as an equivalent SR dose ( $\geq 6 \mathrm{~Gy}$ ). In addition, $\mathrm{CD}$ and eEF1 were valuable biomarkers of cellular senescence in either SR- or RF-exposed carcinoma cells or xenograft mice. Our results suggest that $2 \mathrm{~Gy}$ of a conventional RT regime could achieve a better clinical outcome if prema-
\end{abstract}

Correspondence to: Dr Jae-Seon Lee, Division of Biomedical Sciences, College of Medicine, Inha University, Sinheung-dong 3-ga, Jung-gu, Incheon 400-712, Republic of Korea

E-mail: jaeslee@inha.ac.kr

Dr Young-Gyu Ko, Division of Life Sciences, Korea University, Seoul 136-701, Republic of Korea

E-mail:ygko@korea.ac.kr

${ }^{*}$ Contributed equally

Key words: premature senescence, biomarker, single irradiation, fractionated irradiation, cancer ture senescence could be increased through an improved understanding of its molecular action mechanism.

\section{Introduction}

Ionizing radiation (IR)-induced apoptosis has been known to play a primary role in the therapeutic effect of IR. Many studies have addressed the mechanism of IR-induced apoptosis and the most effective strategies to induce it in radiotherapy (RT)-targeted cancer cells (1-4). However, it has been reported that apoptosis may not be the exclusive or even the primary mechanism underlying tumor regression due to cancer therapy; many studies have indicated that premature senescence also plays a crucial role in tumor regression as well as cancer prevention (5-7). Cellular senescence is induced by a variety of signals, such as telomere shortening, oncogene activation, ROS and DNA damage $(8,9)$. Senescent cells undergo functional and morphological changes including senescenceassociated $\beta$-galactosidase (SA- $\beta$-Gal) activity and large and flat morphology $(10,11)$. Previous studies showed that cancer cells may become prematurely senescent rather than apoptotic in response to DNA damage depending on cellular context, although the mechanism of this alternate response is unclear. Senescent cells are found in pre-malignant lesions in mice and humans, and induction of senescence prevents malignant progression in certain mouse tumor models (12-14). Premature senescence may be induced in cancer cells using lower doses of a drug than required to induce apoptosis $(15,16)$, indicating that cancer therapies targeting cellular senescence may reduce damage of normal tissues. However, despite the interest in the clinical application of premature senescence to increase RT efficacy, its importance in IR-exposed cells or tissues remains to be further validated.

$\mathrm{RT}$ is an essential therapeutic modality for a wide range of malignant tumors. Although 40-60\% of cancer patients receive $\mathrm{RT}$, its clinical usage is hindered by the significant morbidity of radiation-induced injury to surrounding normal tissue. A major challenge in radiation oncology is minimizing 
the detrimental effects of RT on normal tissue while maximizing its tumoricidal effects $(17,18)$. Fractionated radiation (FR) treatment reduces the damage to the surrounding normal cells while maintaining the probability of tumor control (19). In the clinical setting, the total IR dose is carefully determined and is often fractionated to reduce the injury to normal tissues. Due to differences in the repair of sub-lethal damage in normal vs. tumor cells, 2 Gy fractional doses are typically used in conventional FR $(20,21)$. It is not well known whether FR or any IR modality effectively induces premature senescence in vivo, mainly due to the shortage of reliable biomarkers of senescence as well as the technical difficulty of validating permanent cell cycle arrest. Although several novel markers of senescence have been identified $(15,22)$, their reliability, diagnostic and prognostic values require further characterization.

In the present study, we assessed IR-induced cancer cell senescence and senescence biomarkers in vitro and in vivo, and compared the relative effectiveness of single radiation (SR) vs. FR.

\section{Materials and methods}

Cell culture and animals. $\mathrm{H} 460$ and MCF7 cells were cultured as described by Byun et al (15). Female BALB/c athymic nude mice (Orient Co., Seongnam, Korea) were maintained and studied as described by Byun et al (15).

Antibodies. Rabbit anti-eEF1A1 and anti-eEF1B2 antibodies were purchased from Abcam (Cambridge, MA, USA). Rabbit anti-phospho-pRb and mouse anti-p53 antibodies were purchased from Cell Signaling Technology (Danvers, MA, USA) and Novocastra Inc. (Newcastle, UK), respectively. Rabbit anti-p21, goat anti-cathepsin D, rabbit anti-DcR2, mouse anti-DEC1, goat anti- $\beta$-actin, and horseradish peroxidase-conjugated secondary antibodies were obtained from Santa Cruz Biotechnology (Santa Cruz, CA, USA).

Irradiation. Cells were irradiated to $\gamma$-ray with ${ }^{137} \mathrm{Cs} \gamma$-ray source (Atomic Energy of Canada Ltd., Mississauga, Canada) at a dose rate of $3.2 \mathrm{~Gy} / \mathrm{min}$. Irradiation of cells was based on three single irradiation doses (2, 6 and $12 \mathrm{~Gy})$, while fractionated irradiation of cells was conducted daily to $2 \mathrm{~Gy}$ three times with $4 \mathrm{~h}$ time intervals for single day or two consecutive days ( $3 \times 2$ Gy or $6 \times 2$ Gy). Local regional irradiation of xenografted tumor was performed under anesthesia using $a^{6}{ }^{60} \mathrm{Co}$ source irradiator (Theratron 780; Atomic Energy of Canada Ltd.) operating at $1.3 \mathrm{~Gy} / \mathrm{min}$. When xenografted tumor volume reached $200-250 \mathrm{~mm}^{3}$, xenografted regions of mice were exposed to SR or FR with the same procedures. Mice were sacrificed for further experiments at 1 and 7 days after the last IR exposure.

Relative cell number, clonogenicity, SA- $\beta$-Gal staining and western blotting. Analyses of relative cell number, clonogenicity, SA- $\beta-$ Gal activity and western blotting were performed as described by Byun et al (15).

Xenograft mouse model. $\mathrm{H} 460$ lung cancer cells $\left(5 \times 10^{6}\right.$ cells $)$ were injected subcutaneously to the right side proximal hind legs of 6 week-old nude mice. Xenograft tumor growth was monitored every day by measuring tumor width and length using a digital caliper. Tumor volume was calculated by the following equation: Volume $=0.5 \times \mathrm{Width}^{2} \mathrm{x}$ Length.

Terminal deoxynucleotidyl transferase dUTP nick end labeling assay. Apoptosis in tumor tissue was assayed using terminal deoxynucleotidyl transferase dUTP nick end labeling (TUNEL) assay kit (ApopTag ${ }^{\circledR}$ Peroxidase In Situ Apoptosis detection kit; Millipore, Temecula, CA, USA) following the manufacturer's protocol. Sections were counterstained with hematoxylin. Negative control sections were incubated with distilled water in the absence of TdT.

Immunohistochemistry. Tumor tissues from xenografted mice were fixed and embedded in paraffin. Immunohistochemistry was performed with the Vectastain Elite ABC kit (Vector Laboratories Inc., Burlingame, CA, USA) following the manufacturer's protocol. Immunoreactive sites were visualized by 3,3'-DAB. Subsequently, the slices were counterstained by hematoxylin.

\section{Results}

Effect of SR and FR on premature senescence in carcinoma cell lines. To investigate whether equivalent total doses of SR or FR induced premature senescence, we exposed MCF7 and $\mathrm{H} 460$ carcinoma cells to a range of doses of SR (2, 6 or $12 \mathrm{~Gy})$ or FR ( $3 \times 2$ Gy or 6 x 2 Gy). In both cell lines, 6 or 12 Gy SR dose-dependently decreased clonogenicity and relative cell number, increased SA- $\beta-$ Gal activity and induced large and flat cell morphology (Figs. 1A-C and 2A-C). The percentage of cells that underwent cell death after SR exposure was up to $20 \%$ in time- and dose-dependent manners in both cell lines (Figs. 1D and 2D). These results indicate that either 6 or 12 Gy SR effectively induced cellular senescence rather than cell death. Since RT is conventionally delivered in fractions of 2 Gy, we compared the effects of 6 or 12 Gy FR on MCF7 and H460 cells (Figs. 1 and 2). The same total dose of FR resulted in similar effects as SR on clonogenicity, relative cell number and cell death in both cell lines. Thus, our data demonstrate that premature senescence is the major response of carcinoma cells to 6 or 12 Gy of IR, regardless of SR or FR.

Evaluation of senescence markers in SR-or FR-exposed carcinoma cell lines. We reported CD, eEF1A1 and eEF1B2 and others have reported DcR2 and Dec1 as senescence markers $(15,22)$; however, the reliability of these markers requires further validation. We examined expression changes of these markers during premature senescence in SR- or FR-exposed cells (Fig. 3). In either cell line, expression of $\mathrm{CD}$ was increased and eEF1A1 and eEF1B2 were decreased by 6 or 12 Gy of SR or FR. Notably, p53 and p21 accumulated not only in 6 or $12 \mathrm{~Gy}$ of SR- or FR-exposed cells, but also in 2 Gy of SR-exposed cells which did not undergo either apoptosis or cellular senescence. The changes in expression of CD, eEF1A1 and eEF1B2 closely correlated with hypophosphorylation of $\mathrm{pRb}$, a reliable indication of cell cycle arrest. In contrast to the report of increased Dec1 and DcR2 expression in oncogene-induced prematurely senescent tumor cells (13), after IR exposure in our experiments, DcR 2 expression decreased in both cell lines 
$\mathbf{A}$

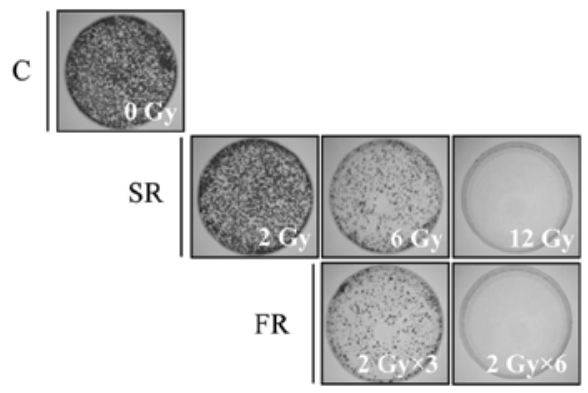

C

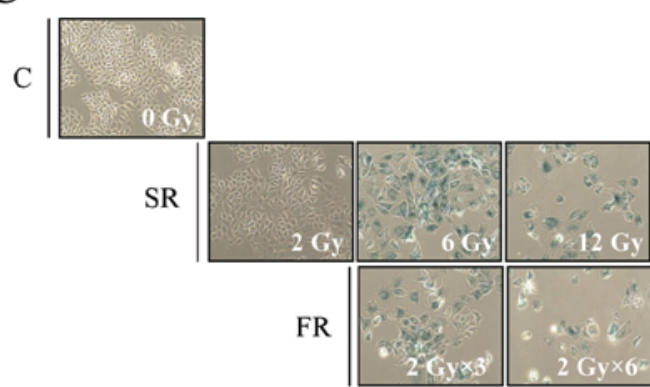

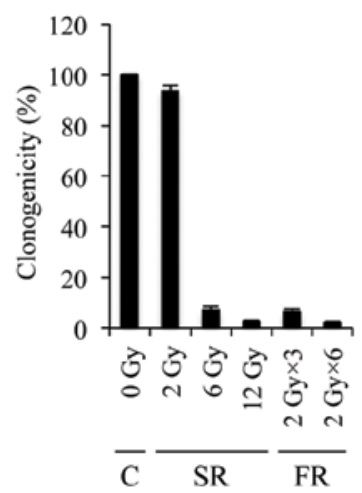

B

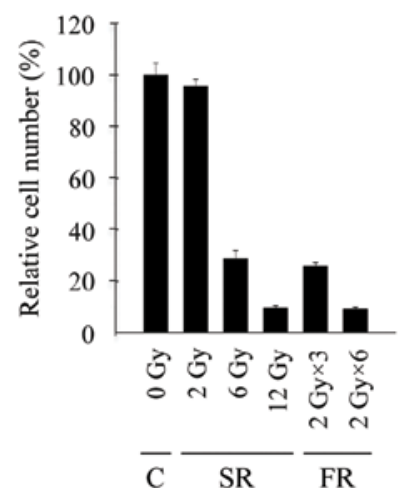

D
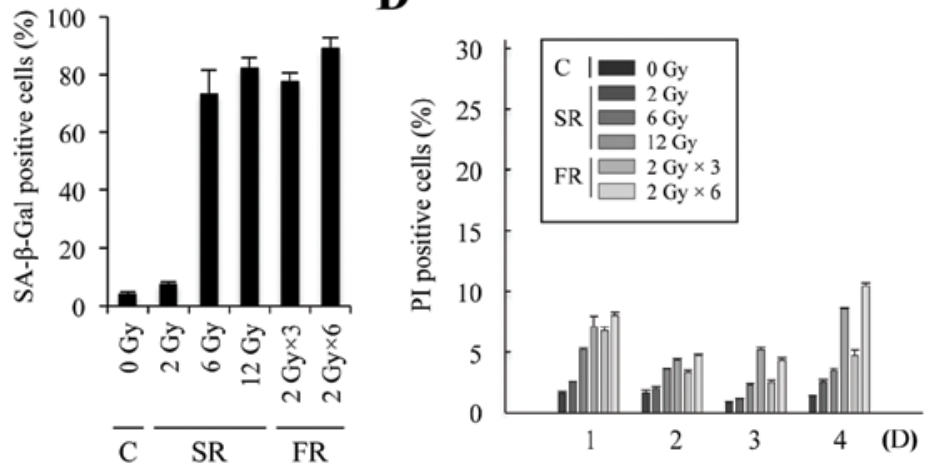

Figure 1. The cellular response in SR- or FR-exposed MCF7 cells. (A) Clonogenicity and (B) relative cell number were decreased by 6 or 12 Gy of SR or FR. (C) Phase contrast images of SA- $\beta$-Gal-stained cells (blue). Note the large and flat morphology of SA- $\beta$-Gal-positive cells. (D) Propidium iodide (PI) positivity increased in IR-exposed cell cultures. Clonogenicity was assessed at 7 days, and relative cell number and SA- $\beta$-Gal positivity were examined 4 days after exposure to various doses of SR (2, 6 or 12 Gy) or FR ( 3 x 2 Gy or 6 x 2 Gy). C, unexposed control cells; SR, single radiation; FR, fractionated radiation.

A

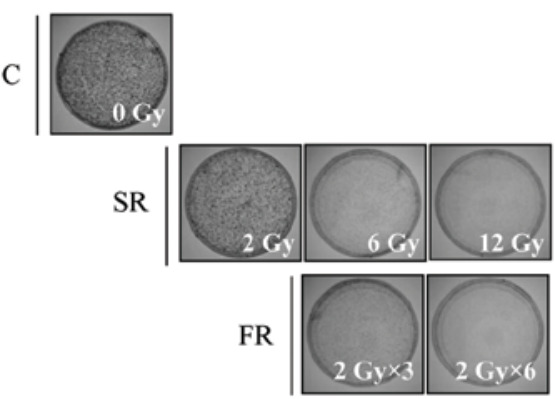

C

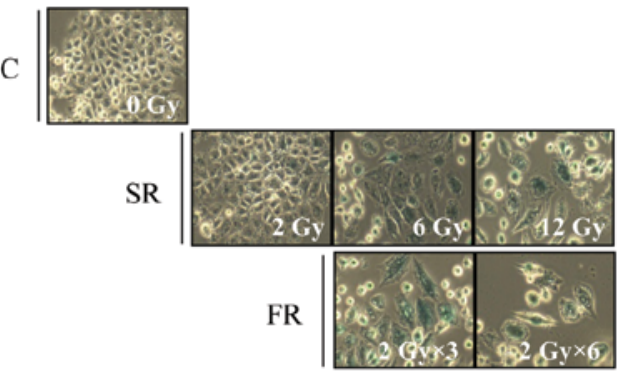

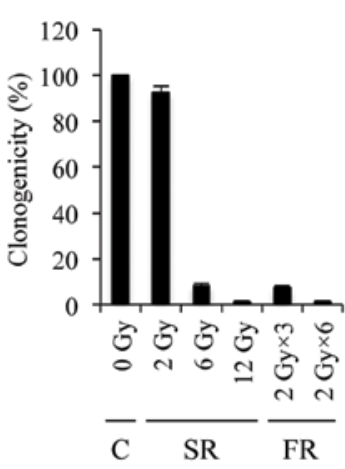

D

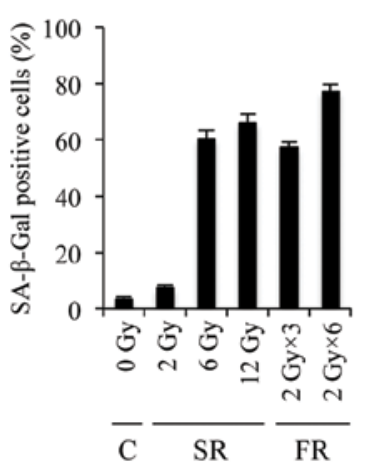

B
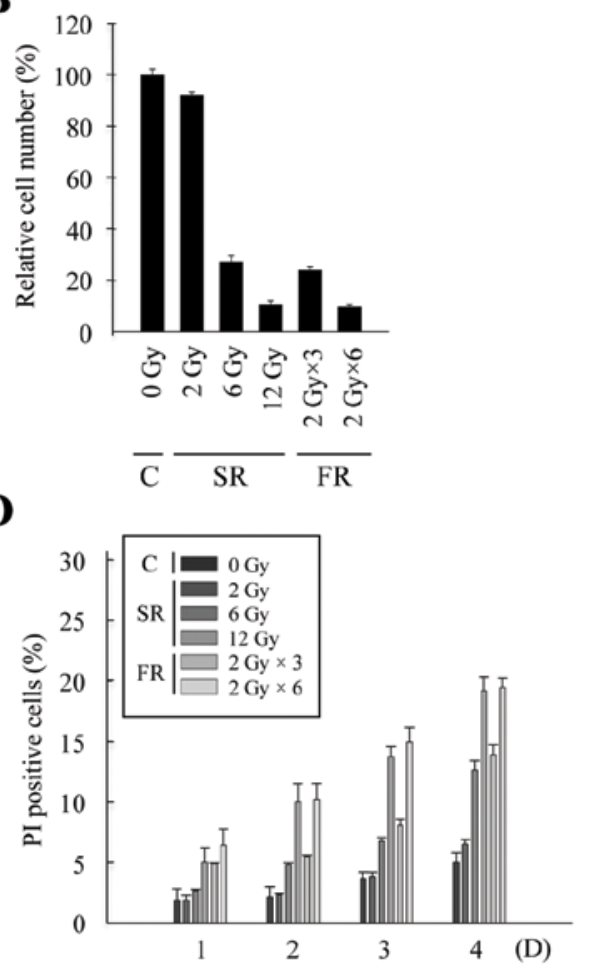

Figure 2. The cellular response in SR- or FR-exposed H460 cells. (A) Clonogenicity and (B) relative cell number were decreased by 6 or 12 Gy of SR or FR. (C) Phase contrast images of SA- $\beta$-Gal-stained cells (blue). Note the large and flat morphology of SA- $\beta$-Gal-positive cells. (D) Propidium iodide (PI) positivity increased in IR-exposed cell cultures. Clonogenicity, relative cell number, and SA- $\beta$-Gal positivity were analyzed as described in Fig. 1 . C, unexposed control cells; SR, single radiation; FR, fractionated radiation. 


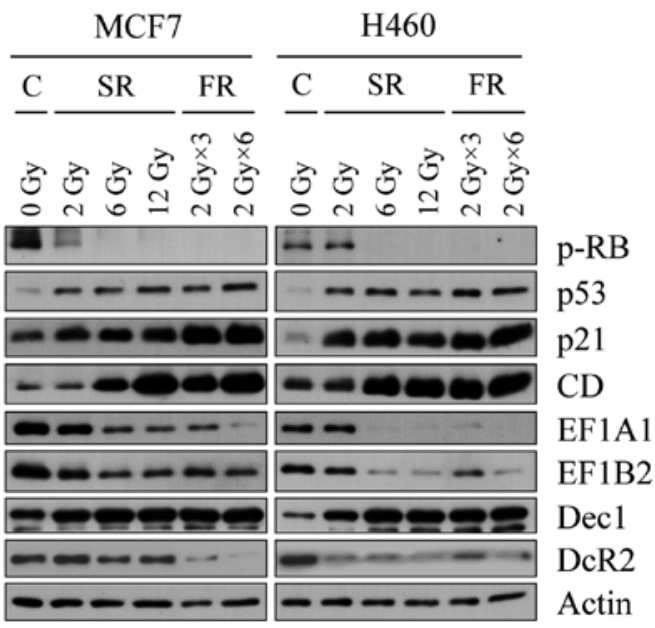

Figure 3. Expression of the indicated proteins in irradiated MCF7 and H460 cells. Western blot analyses using specific antibody for each protein were performed using cell lysates obtained 4 days following exposure to the indicated doses of SR (2, 6 or 12 Gy) or FR ( 3 x 2 Gy or 6 x 2 Gy). C, unexposed control cells; SR, single radiation; FR, fractionated radiation.

and Dec1 was evidently increased only in H460 cells. These data indicate that IR exposure induced senescence effectively in either SR ( 6 or 12 Gy)- or FR ( 3 x 2 Gy or 6 x 2 Gy)-exposed $\mathrm{H} 460$ and MCF7 cells, and we further validated CD, eEF1A1 and eEF1B2 as valuable markers of cellular senescence.

Effect of SR and FR on apoptosis, cell proliferation and premature senescence in tumor tissue of xenograft mice. We next examined whether IR-induced premature senescence was involved in inhibition of tumor growth in vivo. We developed a mouse xenograft model by subcutaneously transplanting H460 cells in athymic nude mice and exposed mice to either SR or FR (Fig. 4A). The xenograft tumor volume was markedly reduced in a dose-dependent manner following FR and SR exposure (Fig. 4B).

A

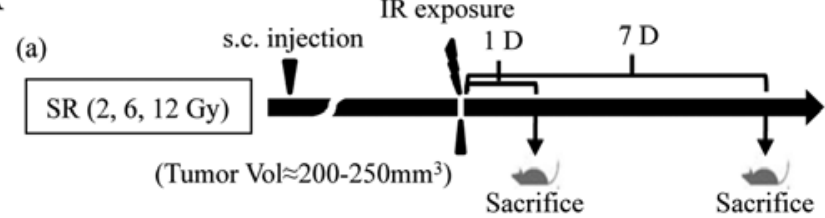

(b)

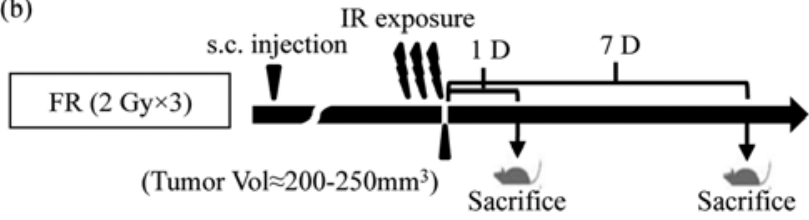

(c)

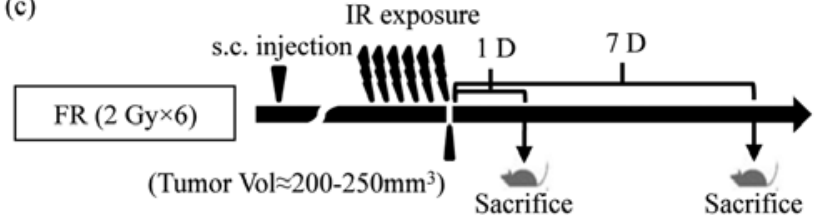

Xenograft tumors were processed for histology and stained with hematoxylin and eosin (H\&E) (Fig. 5A). To assess apoptosis, we performed TUNEL assays and found no marked change in IR-induced apoptosis at any IR dose or time examined (Fig. 5A). We next assessed cell proliferation and premature senescence using $\mathrm{Ki}-67$ immunostaining and SA- $\beta$-Gal staining, respectively. Cellular proliferation was obviously decreased by either 6 or 12 Gy SR or FR exposure (Fig. 5B). SA- $\beta$-Gal staining was strongly apparent 7 days after exposure to 6 or 12 Gy of either SR or FR (Fig. 5B). The Ki-67 and SA- $\beta$-Gal labeling indices showed that the effects at 7 days were dose-dependent (Fig. 5C). SR and FR were equally effective at inducing SA- $\beta$-Gal positivity. These results indicate that IR-induced inhibition of cell proliferation may be related to the induction of premature senescence, and that FR was as effective as SR at inducing premature senescence.

Finally, we analyzed expression of the senescence biomarkers in the irradiated xenograft tumors (Fig. 6). Expression of p53 was not altered by any dose of IR, in contrast to the in vitro result, whereas $\mathrm{p} 21$ and $\mathrm{CD}$ expression increased after 6 or 12 Gy IR exposure, particularly 7 days following FR. Expression of eEF1A1 and eEF1B2 were both decreased 7 days after exposure to 6 or 12 Gy of SR or FR. The effects of FR on expression of $\mathrm{p} 21, \mathrm{CD}$, eEF1A1 and eEF1B2 were more pronounced than the effects of SR (Fig. 6). In contrast, SR or FR did not alter expression of Dec1 and DcR2, indicating that these were not markers for premature senescence in this context. Changes in expression of $\mathrm{CD}$, eEF1A1 and eEF1B2 in vivo (Fig. 6) were consistent with the in vitro findings (Fig. 3) and are further support that $\mathrm{CD}$, eEF1A and eEF1B2 are promising senescence biomarkers for clinical application.

\section{Discussion}

RT is based on eliminating the disease by depriving the proliferative potential of the tumor cells. Frequently, the desired effect of tumor treatment is achieved through the promotion

B

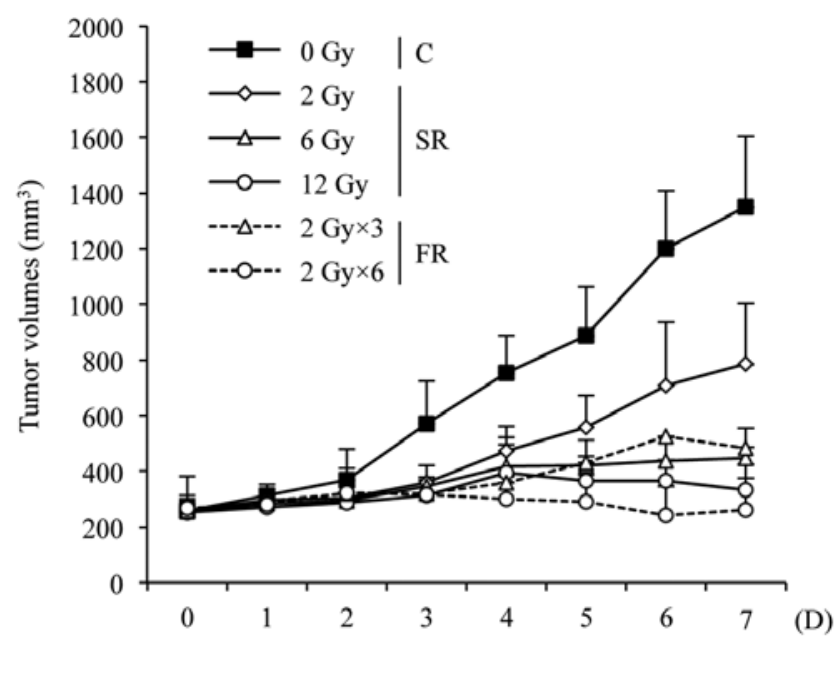

Figure 4. In vivo experimental protocol and tumor growth rate. (A) Schematic drawing of in vivo experimental protocol. (B) Measurement of tumor volume after exposure of xenografted mice to SR or FR. When xenografts reached a volume of 200-250 mm ${ }^{3}$, mice were exposed to SR ( 2 , 6 and 12 Gy) or FR ( 3 x 2 Gy or $6 \times 2$ Gy) and tumor volumes were measured every day up to 7 days. C, unexposed control cells; SR, single radiation; FR, fractionated radiation. 
A
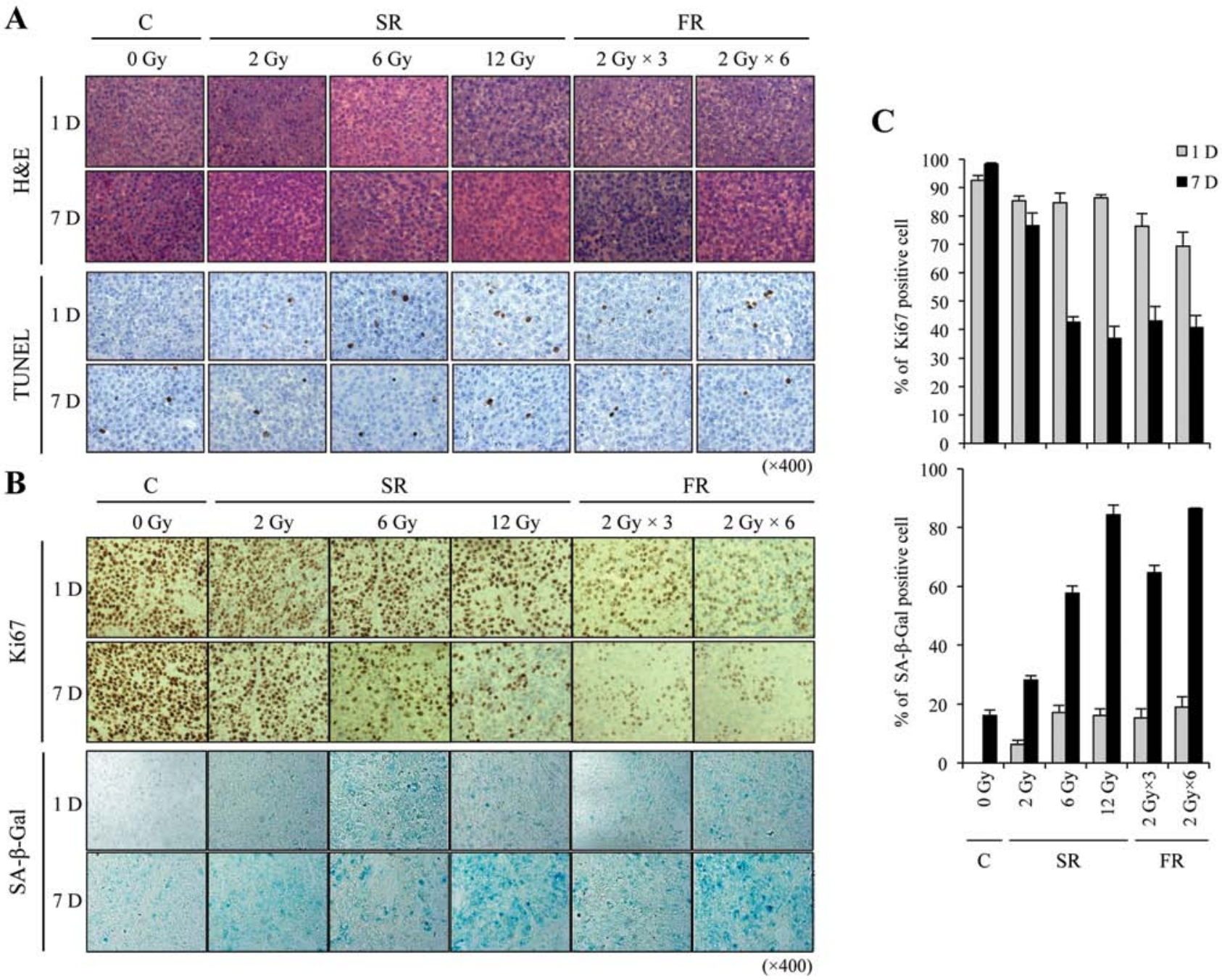

Figure 5. Evaluation of premature senescence in tumor tissues of xenografted mice exposed to SR or FR. (A) H\&E staining and TUNEL assay (brown precipitate). (B) Ki-67 immunostaining (brown) and SA- $\beta$-Gal activity (blue) in tumor sections derived from xenografted mice exposed to either SR or FR (C) Quantification of Ki-67 immunostaining and SA- $\beta$-Gal positivity. C, unexposed control cells; SR, single radiation; FR, fractionated radiation.

SR

\begin{tabular}{|c|c|}
\hline $1 \mathrm{D}$ & $7 \mathrm{D}$ \\
\hline $12 \mathrm{~Gy}$ & $12 \mathrm{~Gy}$ \\
\hline $\begin{array}{llllllllllll}1 & 2 & 3 & 1 & 2 & 3 & 1 & 2 & 3 & 1 & 2 & 3\end{array}$ & $\begin{array}{llllllllllll}1 & 2 & 3 & 1 & 2 & 3 & 1 & 2 & 3 & 1 & 2 & 3\end{array}$ \\
\hline - & - \\
\hline 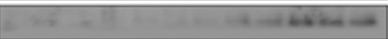 & $-2=0-2$ \\
\hline 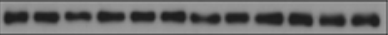 & 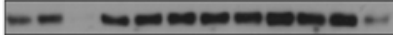 \\
\hline -00-- & 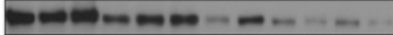 \\
\hline 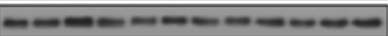 & 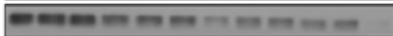 \\
\hline 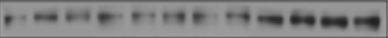 & 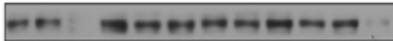 \\
\hline 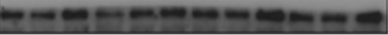 & 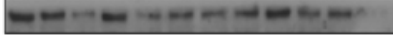 \\
\hline-2 & \\
\hline
\end{tabular}

FR

\begin{tabular}{|c|c|}
\hline $1 \mathrm{D}$ & $7 \mathrm{D}$ \\
\hline C $2 \mathrm{~Gy} \times 3 \quad 2 \mathrm{~Gy} \times 6$ & C $2 \mathrm{~Gy} \times 3 \quad 2 \mathrm{~Gy} \times 6$ \\
\hline $\begin{array}{lllllllll}1 & 2 & 3 & 1 & 2 & 3 & 1 & 2 & 3\end{array}$ & $\begin{array}{lllllllll}1 & 2 & 3 & 1 & 2 & 3 & 1 & 2 & 3\end{array}$ \\
\hline$-\infty-\pi-\infty-\infty$ & 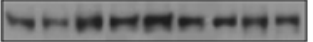 \\
\hline$-\rightarrow+n-6=0$ & -----1 \\
\hline 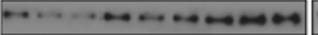 & 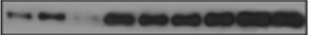 \\
\hline - & 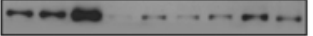 \\
\hline 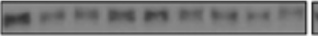 & 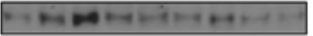 \\
\hline 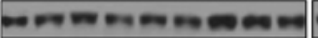 & 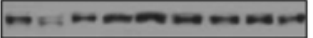 \\
\hline$\Delta-\cdots+\cdots \cdots$ & r-m-n \\
\hline 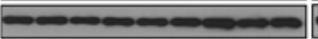 & 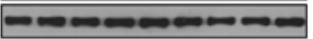 \\
\hline
\end{tabular}

Figure 6. Expression of the indicated proteins in tumor tissue of xenografted mice exposed to either SR or FR. Western blot analyses were performed with specific antibody for each protein in tissue lysates obtained from three mice per group at 1 or 7 days post-irradiation. C, unexposed control cells; SR, single radiation; FR, fractionated radiation.

of apoptosis, particularly in solid tumors (23-25). Although failure to undergo apoptosis in response to radiation may be a mechanism of radiation resistance, it is gradually being recognized that the loss of reproductive capacity in solid tumors can occur through alternative pathways including mitotic catastrophe, autophagic cell death and cellular senescence $(26,27)$. Haugstetter et al (28) showed that senescence index could predict the treatment outcome in 30 metastatic colorectal 
cancer patients. Our data showed that premature senescence rather than apoptosis is the predominant response in vitro and in vivo to either 6 or 12 Gy of SR or FR (Figs 1, 2 and 5). Apoptotic cells were rare in vivo 1 or 7 days after SR or FR exposure (Fig. 5A). As the in vivo system may be more clinically relevant than in vitro culture, this suggests that apoptosis may not be the principal mechanism of IR-mediated tumor regression in the clinical situation. Chang et al (29) demonstrated that induction of senescence-like phenotype seems to be common response to IR under the conditions of minimal cytotoxicity, providing the evidence that senescence may be an important determinant of cancer treatment outcome. Of note, IR exposure is effective at reducing tumor cell proliferation through multiple mechanisms, depending on the complexity of the cellular context (25). We and others found that loss of PTEN activity in either glioma cells or a mouse model of prostate cancer results in widespread premature senescence rather than apoptosis $(12,25)$. Ruth and Roninson $(30)$ reported that expression of P-glycoprotein (Pgt) inhibits IR-induced apoptosis. However, this effect of Pgt had no effect on radiation resistance since inhibition of apoptosis is associated with a concurrent increase in mitotic catastrophe and senescence in SR-damaged cells. Adjunctive therapy of tyrosine kinase inhibitor or poly(ADP-ribose) polymerase inhibitor with SR potentiates terminal growth arrest associated with senescence in vitro and in vivo, suggesting that tumor cell senescence is a mechanism for tumor targeting therapy in combination with IR $(31,32)$. DeMasters et al $(33)$ demonstrated that vitamin D3 analog delayed FR (5 × 2 Gy)-induced senescence arrest in breast cancer cells. Based on these results, not only the genetic background of the cancer patients but also the drug selection for combinational treatment should be carefully considered when predicting the primary mechanism underlying tumor regression after RT. Further studies are needed to elucidate how widespread this phenomenon may be and whether premature senescence practically contributes to the treatment outcome in animal models and cancer patients.

Molecular changes associated with cell cycle arrest, such as changes in phospho- $\mathrm{Rb}, \mathrm{p} 53$ and p21 in IR-exposed cells occurred in similar patterns in SR- and FR-treated cells. However, since these molecules change under the conditions of not only permanent cell cycle arrest but also transient cell cycle arrest, they are indicators of cell cycle arrest (15). Expression of $\mathrm{CD}$, eEF1A1 and eEF1B2 was evidently altered in cells exposed to the same total doses of SR or FR (6 or 12 Gy; Figs. 3 and 6) and were not altered in transient cell cycle arrest (15). $\mathrm{CD}, \mathrm{eEF} 1 \mathrm{~A} 1$ and eEF1B2 expression correlated more closely with the SA- $\beta-$ Gal labeling index than the accumulation of p53 and p21 did (Figs. 3 and 6), providing further support of our previous report that these molecules are promising markers for the detection of senescence (15). Expression of CD, eEF1A1 and eEF1B2 in vivo was more sensitive to FR than SR (Fig. 6), indicating that conventional FR could be the preferred regimen for inducing premature senescence. However, since we did not detect any change in DcR2 in IR-induced senescent cells, neither in vitro nor in vivo, DcR2 expression may depend upon the specific cellular context and may not be a general marker for cellular senescence. Similarly, although Dec1 expression increased following SR or FR exposure in vitro, Dec1 expression did not correlate with cellular senescence in vivo (Figs. 3 and 6). Although several recently identified biomarkers, such as HP1 $\alpha$, PML, p16, p15 and ${ }^{12} \mathrm{C}-\mathrm{FDG}$ may indicate cellular senescence, these need to be further evaluated before their clinical application in vivo $(13,24,27,28,34)$. SA- $\beta$-Gal activity assay is the gold standard for senescence detection but is not suitable for clinical use since it is an enzymatic assay that requires fresh, frozen tissue sections (24). Our results strongly suggest that analysis of $\mathrm{CD}, \mathrm{eEF} 1 \mathrm{~A} 1$ and eEF1B2 expression in combination with $\mathrm{p} 21, \mathrm{pRB}$ and proliferation markers such as $\mathrm{Ki}-67$ or poly(ADP-ribose) polymerase, is a promising method to assess senescence in vitro and in vivo.

In summary, we have shown that premature senescence was the predominant pathway for IR-mediated tumor regression in vitro and in vivo, in response to 6 and 12 Gy of either SR or FR. Reliable assays for senescence may provide prognostic value on IR-mediated tumor regression in clinically relevant situations, and might be a more accurate prognostic factor than the apoptotic index in the treatment of solid tumors. Moreover, our data further support that $\mathrm{CD}, \mathrm{eF} 1 \mathrm{~A} 1$ and $\mathrm{eEF} 1 \mathrm{~B} 2$ are promising biomarkers for the detection of IR-induced premature senescence in vivo. Our data may contribute to the clinical application of premature senescence for the prediction of RT outcome.

\section{Acknowledgements}

The present study was supported by the Nuclear Research and Development Program of the National Research Foundation grant funded by the Korean government (MSIP) (2012M2B2B1-2012055637).

\section{References}

1. Nomura T, Kinuta M, Hongyo T, Nakajima $\mathrm{H}$ and Hatanaka T: Programmed cell death in whole body and organ systems by low dose radiation. J Radiat Res 33: 109-123, 1992.

2. Hendry JH, Potten CS and Merritt A: Apoptosis induced by highand low-LET radiations. Radiat Environ Biophys 34: 59-62, 1995.

3. Wang Y, Liu L, Pazhanisamy SK, Li H, Meng A and Zhou D: Total body irradiation causes residual bone marrow injury by induction of persistent oxidative stress in murine hematopoietic stem cells. Free Radic Biol Med 48: 348-356, 2010.

4. Bruskov VI, Karp OE, Garmash SA, Shtarkman IN, Chernikov AV and Gudkov SV: Prolongation of oxidative stress by long-lived reactive protein species induced by X-ray radiation and their genotoxic action. Free Radic Res 46: 1280-1290, 2012.

5. Gewirtz DA, Holt SE and Elmore LW: Accelerated senescence: an emerging role in tumor cell response to chemotherapy and radiation. Biochem Pharmacol 76: 947-957, 2008.

6. Collado M and Serrano M: Senescence in tumours: evidence from mice and humans. Nat Rev Cancer 10: 51-57, 2010.

7. Nardella C, Clohessy JG, Alimonti A and Pandolfi PP: Pro-senescence therapy for cancer treatment. Nat Rev Cancer 11: 503-511, 2011.

8. Ben-Porath I and Weinberg RA: The signals and pathways activating cellular senescence. Int J Biochem Cell Biol 37: 961-976, 2005.

9. Ohtani N, Mann DJ and Hara E: Cellular senescence: its role in tumor suppression and aging. Cancer Sci 100: 792-797, 2009.

10. Dimri GP, Lee X, Basile G, Acosta M, Scott G, Roskelley C, et al: A biomarker that identifies senescent human cells in culture and in aging skin in vivo. Proc Natl Acad Sci USA 92: 9363-9367, 1995.

11. Debacq-Chainiaux F, Erusalimsky JD, Campisi J and Toussaint O: Protocols to detect senescence-associated betagalactosidase (SA- $\beta$ gal) activity, a biomarker of senescent cells in culture and in vivo. Nat Protoc 4: 1798-1806, 2009.

12. Chen Z, Trotman LC, Shaffer D, Lin HK, Dotan ZA, Niki M, Koutcher JA, Scher HI, Ludwig T, Gerald W, Cordon-Cardo C and Pandolfi PP: Crucial role of p53-dependent cellular senescence in suppression of Pten-deficient tumorigenesis. Nature 436: 725-730, 2005. 
13. Collado M, Gil J, Efeyan A, Guerra C, Schuhmacher AJ, Barradas M, Benguría A, Zaballos A, Flores JM, Barbacid M, Beach D and Serrano M: Tumour biology: senescence in premalignant tumours. Nature 436: 642, 2005.

14. Dankort D, Filenova E, Collado M, Serrano M, Jones K and McMahon M: A new mouse model to explore the initiation, progression, and therapy of BRAFV600E-induced lung tumors. Genes Dev 21: 379-384, 2007.

15. Byun HO, Han NK, Lee HJ, Kim KB, Ko YG, Yoon G, Lee YS, Hong SI and Lee JS: Cathepsin D and eukaryotic translation elongation factor 1 as promising markers of cellular senescence. Cancer Res 69: 4638-4647, 2009.

16. Spallarossa P, Altieri P, Aloi C, Garibaldi S, Barisione C, Ghigliotti G, Fugazza G, Barsotti A and Brunelli C: Doxorubicin induces senescence or apoptosis in rat neonatal cardiomyocytes by regulating the expression levels of the telomere binding factors 1 and 2. Am J Physiol Heart Circ Physiol 297: H2169-H2181, 2009.

17. Nübel T, Damrot J, Roos WP, Kaina B and Fritz G: Lovastatin protects human endothelial cells from killing by ionizing radiation without impairing induction and repair of DNA doublestrand breaks. Clin Cancer Res 12: 933-939, 2006.

18. Rübe CE, Fricke A, Wendorf J, Stützel A, Kühne M, Ong MF, Lipp P and Rübe C: Accumulation of DNA double-strand breaks in normal tissues after fractionated irradiation. Int $\mathrm{J}$ Radiat Oncol Biol Phys 76: 1206-1213, 2010.

19. Kalderon N, Xu S, Koutcher JA and Fuks Z: Fractionated radiation facilitates repair and functional motor recovery after spinal cord transection in rat. Brain Res 904: 199-207, 2001.

20. Dearnaley DP, Khoo VS, Norman AR, Meyer L, Nahum A, Tait D, Yarnold $\mathrm{J}$ and Horwich A: Comparison of radiation sideeffects of conformal and conventional radiotherapy in prostate cancer: a randomised trial. Lancet 353: 267-272, 1999.

21. Munshi A and Budrukkar A: Hypofractionated radiation therapy in breast cancer: a revolutionary breakthrough or a long way to go? J Clin Oncol 25: 458-459, 2007.

22. Collado M and Serrano M: The power and the promise of oncogene-induced senescence markers. Nat Rev Cancer 6: 472-476, 2006

23. Suzuki M and Boothman DA: Stress-induced premature senescence (SIPS) - influence of SIPS on radiotherapy. J Radiat Res 49: 105-112, 2008.

24. Lee JJ, Lee JH, Ko YG, Hong SI and Lee JS: Prevention of premature senescence requires JNK regulation of $\mathrm{Bcl}-2$ and reactive oxygen species. Oncogene 29: 561-575, 2010.
25. Lee JJ, Kim BC, Park MJ, Lee YS, Kim YN, Lee BL and Lee JS: PTEN status switches cell fate between premature senescence and apoptosis in glioma exposed to ionizing radiation. Cell Death Differ 18: 666-677, 2011

26. Chen WS, Yu YC, Lee YJ, Chen JH, Hsu HY and Chiu SJ: Depletion of securin induces senescence after irradiation and enhances radiosensitivity in human cancer cells regardless of functional p53 expression. Int J Radiat Oncol Biol Phys 77: 566-574, 2010.

27. Jackson JG, Post SM and Lozano G: Regulation of tissue- and stimulus-specific cell fate decisions by p53 in vivo. J Pathol 223 127-136, 2011.

28. Haugstetter AM, Loddenkemper C, Lenze D, Gröne J, Standfuss C, Petersen I, Dörken B and Schmitt CA: Cellular senescence predicts treatment outcome in metastasised colorectal cancer. Br J Cancer 103: 505-509, 2010.

29. Chang BD, Broude EV, Dokmanovic M, Zhu H, Ruth A, Xuan Y, Kandel ES, Lausch E, Christov K and Roninson IB: A senescencelike phenotype distinguishes tumor cells that undergo terminal proliferation arrest after exposure to anticancer agents. Cancer Res 59: 3761-3767, 1999.

30. Ruth AC and Roninson IB: Effects of the multidrug transporter P-glycoprotein on cellular responses to ionizing radiation. Cancer Res 60: 2576-2578, 2000.

31. Podtcheko A, Ohtsuru A, Namba H, Saenko V, Starenki D, Palona I, Sedliarou I, Rogounovitch T and Yamashita S: Inhibition of ABL tyrosine kinase potentiates radiation-induced terminal growth arrest in anaplastic thyroid cancer cells. Radiat Res 165: 35-42, 2006.

32. Efimova EV, Mauceri HJ, Golden DW, Labay E, Bindokas VP, Darga TE, Chakraborty C, Barreto-Andrade JC, Crawley C, Sutton HG, Kron SJ and Weichselbaum RR: Poly(ADP-ribose) polymerase inhibitor induces accelerated senescence in irradiated breast cancer cells and tumors. Cancer Res 70: 6277-6282, 2010.

33. DeMasters GA, Gupta MS, Jones KR, Cabot M, Wang H, Gennings C, Park M, Bratland A, Ree AH and Gewirtz DA: Potentiation of cell killing by fractionated radiation and suppression of proliferative recovery in MCF-7 breast tumor cells by the Vitamin D3 analog EB 1089. J Steroid Biochem Mol Biol 92: 365-374, 2004.

34. Pearson M, Carbone R, Sebastiani C, Cioce M, Fagioli M, Saito S, Higashimoto Y, Appella E, Minucci S, Pandolfi PP and Pelicci PG: PML regulates p53 acetylation and premature senescence induced by oncogenic Ras. Nature 406: 207-210, 2000 . 